\title{
PRECISION DELIVERY OF SEMIOCHEMICALS/ OLFACTORY STIMULI USING A PIEZOELECTRIC SPRAYER
}

\author{
A.M. El-SAYED \\ HortResearch, P.O. Box 51, Lincoln \\ Corresponding author: ael-Sayed@hortresearch.co.nz.
}

In the field of olfactory communication, studying the response of animals to olfactory stimuli is hindered by the general lack of a releasing method that allows a precise release rate to be maintained during the course of an experiment. A novel device for quantitative and dynamic application of semiochemicals was developed that allows precise control of the chemical stimuli emitted from a point source. The piezoelectric sprayer consists of a motor-driven or a geared syringe driver that pushes the syringe slowly at a known constant rate to dispense semiochemicals in solvents through micro tubing to a glass capillary micropipette fixed in a piezoelectric high frequency vibrator. The high-frequency vibration of the capillary tip atomizes the released solution and complete evaporation occurs within a few centimeters of the capillary tip. The ratio of the components of a chemical stimulus can be set and calculated straightforwardly from the dilution factor and the dynamically controllable speed of the syringe plunger. The piezoelectric sprayer permits the delivery of chemical stimulus independent of relative vapor pressures of the components and of environmental factors such as temperature, relative humidity, etc.

\section{PHYTOTOXICITY OF AGROCHEMICAL ADJUVANTS ON AVOCADOS}

\author{
R.E. GASKIN ${ }^{1}$, M.E. HOFSTEE ${ }^{1}$ and G.S. ELLIOTT ${ }^{2}$ \\ ${ }^{1} P P C_{N Z}$ Forest Research, Private Bag 3020, Rotorua \\ ${ }^{2}$ Elliott Chemicals Ltd, P O Box 18-417, Glen Innes, Auckland
}

Corresponding author: robyn.gaskin@forestresearch.co.nz.

\begin{abstract}
Anecdotal evidence suggests avocado trees are highly susceptible to damage by spray adjuvants and, as a result, few New Zealand growers use them in pesticide spray programmes. This is despite the fact that adjuvants have the potential to reduce pesticide spray volumes and improve pest and disease control on this crop. Laboratory testing confirmed that addition of super-spreader adjuvants, Du-Wett@ and Bond ${ }^{\circledR}$ Xtra (Elliott Chemicals Ltd), could increase spray coverage of foliage and fruit by up to 10 times. A subsequent field trial investigated whether the addition of the adjuvants to copper fungicide sprays, applied in $<30 \%$ normal spray volumes throughout a growing season, caused any phytotoxicity on avocado. Adjuvants had no effects on fruit on the tree or on the storage quality of fruit at harvest. Very minor, and transient, phytotoxic symptoms were observed on avocado foliage treated with adjuvant sprays. These effects increased with adjuvant concentration and are considered likely to be a function of inappropriate (i.e. too high) spray volumes. These results indicate that superspreader adjuvants could be used to improve pesticide spray coverage on avocados and that there is little risk of phytotoxicity when the adjuvants are applied at appropriate rates in low spray application volumes.
\end{abstract}

